J. Product. \& Dev., 22(3): 409- 428 (2017)

\title{
SPECTRAL CHARACTERISTICS FOR ESTIMATION HEAVY METALS ACCUMULATION IN WHEAT PLANTS AND GRAIN
}

\author{
Mai M. Amer ${ }^{a} ;$ A. Tyler $^{b} ;$ T. Fouda ${ }^{a} ;$ P. Hunter ${ }^{b} ;$ A. Elmetwalli ${ }^{a}$; Clare \\ Wilson $^{b}$ and Mario Vallejo-Marin ${ }^{b}$ \\ ${ }^{a}$ Agricultural Engineering Dept., Faculty of Agriculture, Tanta University, Egypt \\ ${ }^{b}$ Biological and Environmental Sciences, School of Natural Sciences, University \\ of Stirling , Stirling, Scotland, UK \\ Corresponding author: m.m.amer@stir.ac.uk
}

\section{ABSTRACT}

Plants would the start with step of a metal's pathway starting with the dirt on heterotrophic creatures for example, such that animals and humans, thus the substance from claiming metallic follow components for eatable parts of a plant representable accessible load of these metals that might enter those natural way of life through plants. Around metal elements, $\mathrm{Cu}$ and $\mathrm{Zn}$ would micro nutrients as they are essential in trace concentrations for physiological processes in plants. Furthermore consequently would a critical part from the soil-plantfood continuum. Therefore this study aimed to analyzing the performance of multivariate hyperspectral vegetation indices of wheat (Triticum aestivum L.) in estimating the accumulation of these elements in plant dry mutter and the final product of Egyptian wheat crop irrigated with high concentrations of $\mathrm{Zn}$ and $\mathrm{Cu}$. We applied five concentrations for each element $(0.05,20,40,100$, and $150 \mathrm{ppm}$ of $\mathrm{Zn}$ ) and $(0.02,8,10,12$, and $15 \mathrm{ppm}$ of $\mathrm{Cu})$ to a controlled greenhouse experiment to examine the effect of these concentrations on plant spectral characteristics and study the possibility of using spectroradiometry measurements for identifying the grain content of these metals. The results demonstrated that

The hyperspectral vegetation indices had a potential for monitoring Zn concentration in the plant dry matter. NPCI and PSSR had a highest correlation with $\mathrm{Cu}$ phytoaccumulation into the grains with highest significant level $(P$-Value $<0.01)$ and $(r)$ values $(-0.39$, 0.42).

Conclusively, Results of present study demonstrate that hyperspectral reflectance data, as well as studied VIs appears to have potentials for monitoring the phytoaccumulation of $\mathrm{Zn}$ into above- 
ground parts of wheat. The hyperspectral vegetation indices had insignificant correlation with $\mathrm{Zn}$ accumulation in to the grains, but it had a significant negative relationship with $\mathrm{Cu}$ concentration in grains with low correlation coefficient values.

Key words: Heavy metals, remote sensing, Vegetation indices, detecting stress.

\section{INTRODUCTION}

With advances in satellite, airborne and ground based remote sensing, reflectance data are increasingly being used in agriculture. It's a valuable tool in evaluation, monitoring and management of land, water, crop resources and plant stress detection. One of the important types of the plant stressors is the heavy metals. Some of these heavy metals such as $\mathrm{Cu}, \mathrm{Fe}, \mathrm{Zn}$ and $\mathrm{Mg}$ are essential elements for plant and play important roles in many physiological processes like metabolism, growth and development. Upon literature survey, we found scientific reviews that examine the effect of heavy metals on plant growth and function [4 and 1]. The trace metals exerting toxic effects on plants have been studied for over a century by now but there remains confusion within the literature with regards to their concentrations as micronutrients and as components inducing phytotoxic effects. Nevertheless, many problems arise when cells intake an excess of these essential elements or other heavy metals such as arsenic and lead, which are not known to have any essential functions, but are toxic and cause damages to living organisms. Excessive heavy metals in plants adversely affect plant growth and development [15]. The essential heavy metals $(\mathrm{Cu}, \mathrm{Zn}, \mathrm{Fe}, \mathrm{Mn}$ and $\mathrm{Mo})$ play biochemical and physiological functions in plants and animals. Two major functions of essential heavy metals are the following: (a) Participation in redox reaction, and (b) Direct participation, being an integral part of several enzymes [11].

Copper is an essential heavy metal for higher plants and algae, particularly for photosynthesis [10 and 2].

The inorganic and organic fertilizers (Fertilizer is a substance added to soil to improve plants growth and yield.) are the most important sources of heavy metals to agricultural soil include liming, sewage sludge, irrigation waters and pesticides, sources of heavy metals in the agricultural soils . Waste water also contains heavy metal and when it is applied to crops, it can cause threat to soil and plants growing in that soil. Generally, heavy metals cannot 
be removed completely from waste water and when they enter into the soil, it will interfere with the plant roots and tissues, when these plants are eaten by animals or humans they will enter into food chain [8].

Healthy plants, those capable of maximum growth, are generally expected to have higher chlorophyll pigment concentrations than unhealthy plants. Reduced chlorophyll concentrations are often associated with stressed plants, with variations in total chlorophyll to carotenoid ratios used as stress indicators [9]. Various metal treatments have a negative effect on photosynthetic pigments such as chlorophyll-a, chlorophyll-b and total chlorophyll contents of plants where the photosynthetic pigments decreased with increasing heavy metals level in the soil [5].

The relationships between $\mathrm{Zn}$ concentration and the visible-near infrared spectrum of Triticum aestivum L. were studied by [3] and they found that, the pigment reduced with the increased concentration of $\mathrm{Zn}$ in Triticum aestivum L. Corresponding change in visible/near-infrared reflectance spectra of vegetation was observed. The reflectance spectra increased in the visible light region and the strength of blue shift of the red edge. [12], studied the changes in leaf reflectance spectra $(350-2500 \mathrm{~nm})$ due to metal phytoextraction $(\mathrm{Cd}, \mathrm{Pb}, \mathrm{As}$ and their metal-mixture treatments) into barley plants grown in pots. The results demonstrate the potential use of hyperspectral reflectance data to monitor plant health during phytoremediation process. [13] studied the performance of multivariate vegetation indices of rice in estimating the agriculture soil arsenic content and there results indicated that the three - band VIs might be recommended as an indicator for estimating soil arsenic content.

The present experiment was designed to investigate the possibility of using hyperspectral data for detecting $\mathrm{Cu}$ and $\mathrm{Zn}$ accumulation in plant dry mutter at different growth stages and the accumulation in wheat grains under Copper and Zinc stress. The effect of $\mathrm{Cu}$ and $\mathrm{Zn}$ was monitored, using irrigation water containing $\mathrm{Cu}$ and $\mathrm{Zn}$ singly and in combination, to investigate: (i) the effect of the interaction between $\mathrm{Zn}$ and $\mathrm{Cu}$ on wheat plants; (ii) which VIs are more sensitive to use for detecting the accumulation of these elements.

\section{MATERIALS AND METHODS}

\section{Plant material and experimental design}

A controlled pots experiment (Hydroponics experiment) was executed during the spring season of 2016 at the glass greenhouse at the University of 
Stirling, Stirling, United Kingdom (latitude 56 ${ }^{`} 46.25^{\prime \prime}$, longitude $3^{\circ} 55^{\prime} 4.54^{\prime \prime}$ ) to track the different concentrations of Zinc and Copper on the Egyptian wheat (Triticum aestivum L.). The purpose of this experiment is to construct an index for the heavy metals stress response in Egyptian wheat. The experiment was conducted using pots ( $28 \mathrm{~cm}$ diameter - $10 \mathrm{~L}$ volume) and 25 garden trays (120 $\mathrm{cm} \times 55 \mathrm{~cm}$ ). A total of 100 pots were planted using a planting (growing) media (black peat moss and perlite (1:1)) in a greenhouse. The pots were located inside the trays for caching the extra nutrient solution. Five concentrations of both copper $(0.02,8,10,12$ and $15 \mathrm{ppm})$ and Zinc (0.05, 20, 40, 100 and $150 \mathrm{ppm})$ were used. Different treatments of both elements including 25 treatments were applied to study the ability of using the spectral measurement for predicting the accumulation of the both elements in the plant dry matter and the grain yield. Hoagland nutrient solution was used as a nutrient solution for the control treatment [14] and another 24 solutions were prepared for the micronutrient with different concentrations of $\mathrm{Zn}$ and $\mathrm{Cu}$. The plant samples were collected 4 times during the growing season (At tillering, Inflorescence, flowering and milk development stages). The fresh weight of shoots and leaves were recorded. Subsequently, the plant matter was oven-dried at $70{ }^{\circ} \mathrm{C}$ for 48 hours until constant weight, to obtain the dry weight (DW).

\section{Measurements and data analysis}

\section{- Analytical determinations of metals}

Dry plant material and grains were ground to a fine powder and digested in a microwave with concentrated nitric acid. The metal concentrations were measured using Inductively Coupled Plasma optical emission spectrometry (ICP-OES).

\section{-Canopy hyper spectral reflectance data}

An ASD Field Spec Pro spectroradiometer from Analytical Spectral Devices Inc. (Boulder, Co 80301 USA) was used to measure reflectance from plant canopies at a specific height from the plant canopy using artificial illumination. The reflectance measurements were made in a darkroom to avoid changing light intensity from solar radiation and to have a constant light incident on the plant canopy. This instrument can detect reflected light from the canopy ranging from $325 \mathrm{~nm}$ to $1075 \mathrm{~nm}$, covering the visible near infrared (VNIR) portion of the magnetic spectrum. Each reflectance spectrum was the average of a number of scans (which was adjusted and calculated by the spectroradiometer). The spectral measurements were collected at various growth stages (At tillering, Inflorescence, flowering and milk development stages). 


\section{- Hyperspectral Vis}

Vegetation indices were calculated by combining specific reflectance values along spectral signature. The most represented vegetation indexes were selected to detect differences in the reflectance between healthy (The control treatment) and stressed vegetation in visible and red-edge spectral regions. The VIs for different growing stages was calculated. The considered VIs in this study indicated by (Changwei Tan et al., 2013) and listed in Appendix (1).

\section{-Calculations and statistical analysis}

The chlorophyll concentration was calculated from the SPAD-502 chlorophyll readings (Wood, Reeves, and Himelrick, 1993), using the following equation:

$$
y=0.996 x-1.52
$$

Where $\mathrm{y}$ is the chlorophyll concentration and $\mathrm{x}$ is the SPAD-502 chlorophyll readings $(\mu \mathrm{g} . \mathrm{cm}-2)$.

\section{-Leaf area index (LAI):}

Calculated as a ratio of leaf surface area and the occupied land area of this plant (Elmetwalli, 2008).

\section{Statistical analysis:}

Statistical analysis of spectral and chemical data was performed using $\mathrm{R}$ software and reported at $(\mathrm{P}<0.05)$ significance level. Mean and standard deviation $( \pm \mathrm{SD})$ were computed for all data. Data were statistically tested for significant effects through correlation, linear regression, and multiple regression analysis. Correlation coefficient (Pearson's " $r$ ") between spectral variables was computed.

\section{RESULTS AND DISCUSSIONS}

\section{1-Metal accumulation into the plant dry matter:}

Results of chemical analysis for Zinc and Copper concentration in plant samples at different four dates under different treatments illustrated in Figure ( 1 a). The results shows a high positive correlation between the amount of $\mathrm{Zn}$ 
MAI AMER et al.

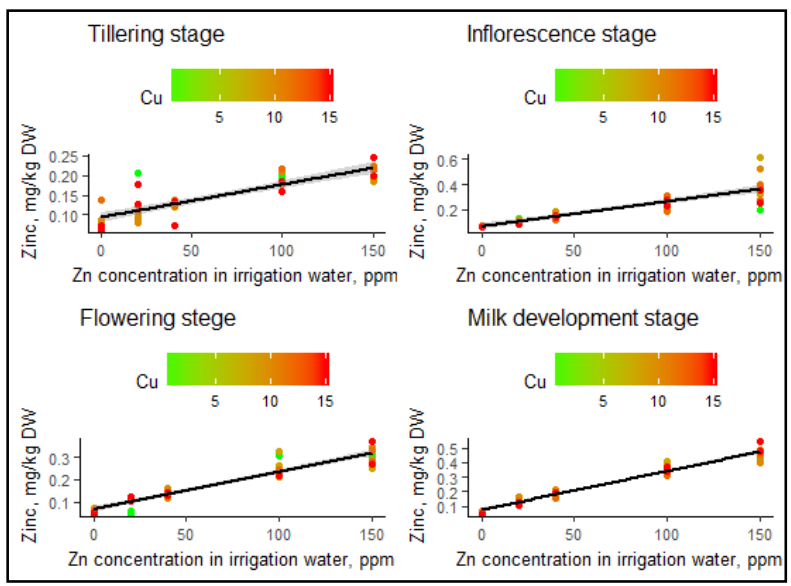

Fig. 1 a: Effect of $\mathrm{Zn}$ level add in irrigation water on the plant dry matter content of Zinc

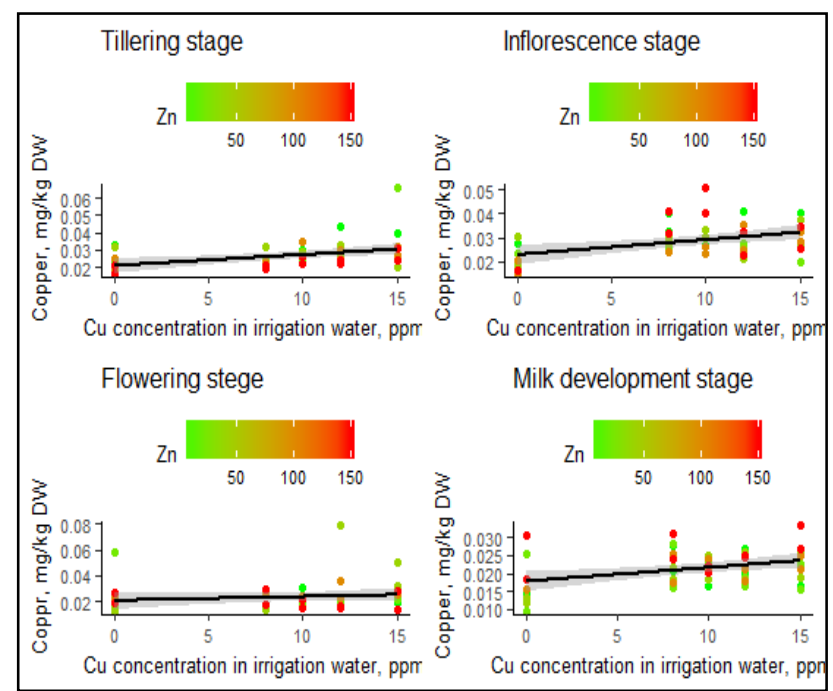

Figure 1 b: Effect of $\mathrm{Cu}$ level add in irrigation water on the plant dry matter content of Copper.

in plant dry matter and the add concentration in irrigation water at different stages $(0.85,0.89,0.95$, and 0.98) with high significant level ( $\mathrm{P}$-value < 0.001) as shown in Table (1). The increasing of $\mathrm{Cu}$ level increased the $\mathrm{Zn}$ accumulation in to the plants, while the higher level of $\mathrm{Zn}$ decreased $\mathrm{Cu}$ 
Table 1: Correlation coefficient, R2, Adj-R2, and P-value for the effect of Zinc, Copper and the interaction between the both elements on the dry matter content of $\mathrm{Zn}$ and $\mathrm{Cu}$

\begin{tabular}{|c|c|c|c|c|c|c|c|c|c|}
\hline \multirow{3}{*}{ 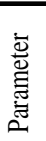 } & \multirow{3}{*}{ Growth stage } & \multicolumn{8}{|c|}{ Source of stress } \\
\hline & & \multicolumn{3}{|c|}{$\mathrm{Zn}$} & \multicolumn{3}{|c|}{$\mathrm{Cu}$} & \multicolumn{2}{|c|}{$\mathrm{Zn} * \mathrm{Cu}$} \\
\hline & & $\mathrm{R}^{2}$ & $\mathrm{P}$ value & $\mathrm{r}$ & $\mathrm{R}^{2}$ & $P$ value & $\mathrm{r}$ & $\mathrm{P}$ value & Adj-R ${ }^{2}$ \\
\hline \multirow{4}{*}{ 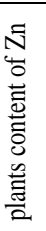 } & Tillering & 0.73 & $0.000^{* * * *}$ & 0.85 & 0.000 & 0.9 & -0.01 & $0.000^{* * * *}$ & 0.72 \\
\hline & Inflorescence & 0.78 & $0.000^{* * *}$ & 0.89 & 0.000 & 0.9 & -0.01 & $0.000^{* * * *}$ & 0.78 \\
\hline & Flowering & 0.91 & $0.000^{* * *}$ & 0.95 & 0.00 & 0.9 & -0.00 & $0.000^{* * * *}$ & 0.91 \\
\hline & $\begin{array}{c}\text { Milk } \\
\text { development }\end{array}$ & 0.96 & $0.000^{* * * *}$ & 0.98 & 0.000 & 0.98 & -0.00 & $0.000^{* * * *}$ & 0.96 \\
\hline \multirow{4}{*}{ 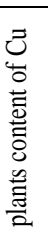 } & Tillering & 0.06 & 0.09 & -0.24 & 0.16 & $0.00^{* * *}$ & 0.4 & $0.00^{* * *}$ & 0.17 \\
\hline & Inflorescence & 0.001 & 0.82 & 0.03 & 0.17 & $0.00^{* * *}$ & 0.41 & $0.02^{*}$ & 0.14 \\
\hline & Flowering & 0.00 & 0.83 & -0.03 & 0.02 & 0.3 & 0.13 & 0.82 & -0.04 \\
\hline & $\begin{array}{c}\text { Milk } \\
\text { development }\end{array}$ & 0.12 & 0.013 & 0.35 & 0.15 & $0.00^{* * *}$ & 0.38 & $0.00^{* * *}$ & 0.22 \\
\hline
\end{tabular}

** A significant effect at $\mathrm{P}$-value $<0.001 * *$ A significant effect at $\mathrm{P}$-value $<0.01 * \mathrm{~A}$ significant effect at $\mathrm{P}$-value $<0.05$

uptake. High zinc concentrations facilitated copper uptake by the roots but reduced its transfer to the aboveground organs [7], as shown in Figure (1 b). The Copper concentration in irrigation water has insignificant effect at significant level $\mathrm{P}$-value $<0.001$ on the dry matter $\mathrm{Cu}$ content but it has a significant positive effect at $\mathrm{P}$-value $<0.01$ we can observe that from R2 $(0.16$, 0.17 , and 0.15 ) and P-values $<0.01$ at Tillering, Inflorescence, and Milk development stages respectively as shown in Table (1). These results confirms the differences in the plant canopy reflectance as a result of plant content of Zinc and Copper.

\section{-Correlation between heavy metal concentrations adds in irrigation water and it's concentration in plant dry mutter:}

To build heavy metal concentration prediction models, the linear regression was used to find the relationships between plant dry mutter content of heavy metals and heavy metal concentrations in irrigation water. 


\section{- Plant dry matter Zn content prediction models}

The $\mathrm{Zn}$ content prediction models showed in table (2) was obtained by linear regression carried out between $\mathrm{Zn}$ content and $\mathrm{Zn}$ levels in irrigation water. Table (2) shows a high correlation between the both factors in different growth stages with high $\mathrm{R}^{2}$ values and high significant $\mathrm{P}$ - value $<0.001$ under the experiment circumstances. The plot of measured plant dry matter content of zinc against predicted $\mathrm{Zn}$ concentration and the results obtained from the testing of the models are displayed in Figure (2). The plot of measured plant dry matter content of Copper against predicted $\mathrm{Cu}$ concentration and the results obtained from the testing of the models are displayed in Figure (3).We were found that the prediction models at different stages predict the dry matter content of $\mathrm{Zn}$ with high significant (P-value $<0.001)$. The correlation coefficient between the measured $\mathrm{Zn}$ concentrations in dry matter and the predicted values was a high positive correlation at different growth stages $(0.85,0.89,0.96$, and 0.98).

Table 2: Validation results of regression models for estimating dry mutter Zinc content depends on two-band hyperspectral vegetation indices

\begin{tabular}{|c|c|c|c|c|c|}
\hline $\begin{array}{c}\text { Two-band } \\
\text { VIs }\end{array}$ & Growth stage & $\begin{array}{c}\text { Curve } \\
\text { shape }\end{array}$ & Fitting model & r & Significantly \\
\hline Zn accumulation in plant dry matter \\
\hline \multirow{2}{*}{ NDVI } & Flowering & Linear & $3.24-3.56$ NDVI & -0.56 & $0.000^{* * * * *}$ \\
\cline { 2 - 7 } & Milk development & Linear & $4.21-4.81$ NDVI & -0.52 & $0.000^{* * * * *}$ \\
\hline \multirow{2}{*}{ SR_680_b } & Flowering & Linear & $0.708-0.04007$ (SR -680-b) & -0.57 & $0.000^{* * * * *}$ \\
\cline { 2 - 7 } & Milk development & Linear & $0.966-0.0686$ (SR -680-b) & -0.54 & $0.000^{* * * *}$ \\
\hline \multirow{2}{*}{ NPQI } & Flowering & Linear & $-0.0410+1.544$ NPQI & 0.59 & $0.000^{* * * * *}$ \\
\cline { 2 - 7 } & Milk development & Linear & $0.0451+1.869$ NPQI & 0.53 & $0.000^{\text {***** }}$ \\
\hline
\end{tabular}




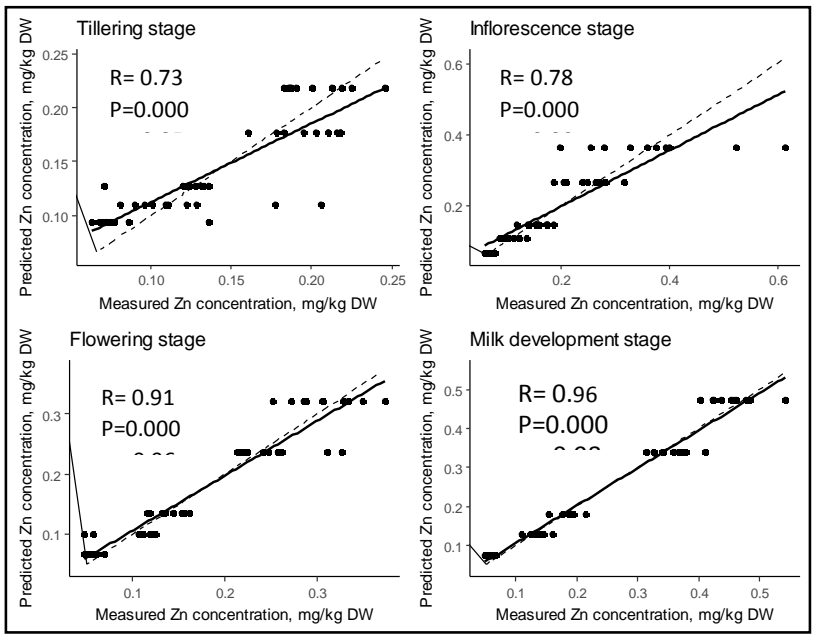

Figure 2: Validation of $\mathrm{Zn}$ effect prediction models on Zinc accumulation in plant dry matter

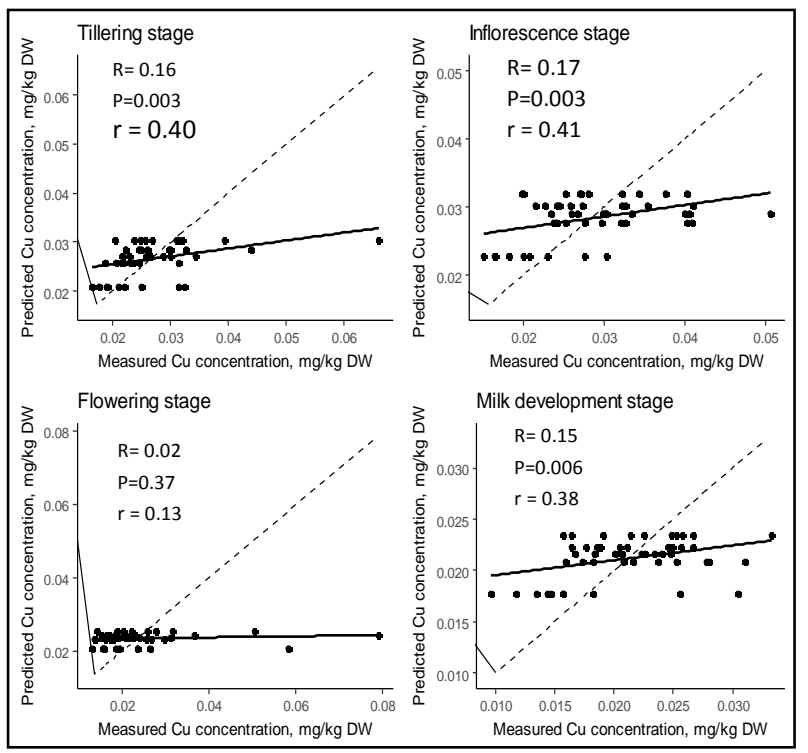

Figure 3: Validation of $\mathrm{Cu}$ effect prediction models on Copper accumulation in plant dry matter.

\section{2-Relationship between two-band vegetation indices and the plant dry mutter content of heavy metals:}

\section{- Zn accumulation:}

All vegetation indices calculated from the dataset and the regression models were validated using the validation dataset. The correlation coefficients (r) between the measured and estimated values of the validation data set were 
applied. Figures ( $4 \mathrm{a}, \mathrm{b}-5 \mathrm{a}, \mathrm{b}-6 \mathrm{a}, \mathrm{b}$ ) show the highest correlated twoband VIs with the $\mathrm{Zn}$ concentration in dry mutter and the statistical models that can be used for detecting the accumulated $\mathrm{Zn}$ in plant dry mutter. We can observe that almost two-band VIs a negative correlation with dry mutter $\mathrm{Zn}$ content, but this negative relationship starts at late growth stage. The negative correlation started to appear at flowering and milk development stages. The highest correlated two-band VIs were NDVI, SR-680-b, and NPQI. NDVI and SR-680-b had a negative correlation with the $\mathrm{Zn}$ accumulation in dry mutter at the flowering and milk development growth stages with high significant level (P-value < 0.001). Figure $(4 \mathrm{a}, \mathrm{b})$ and Figure $(5 \mathrm{a}, \mathrm{b})$ show the relationship of plant dry mutter $\mathrm{Zn}$ content against NDVI and
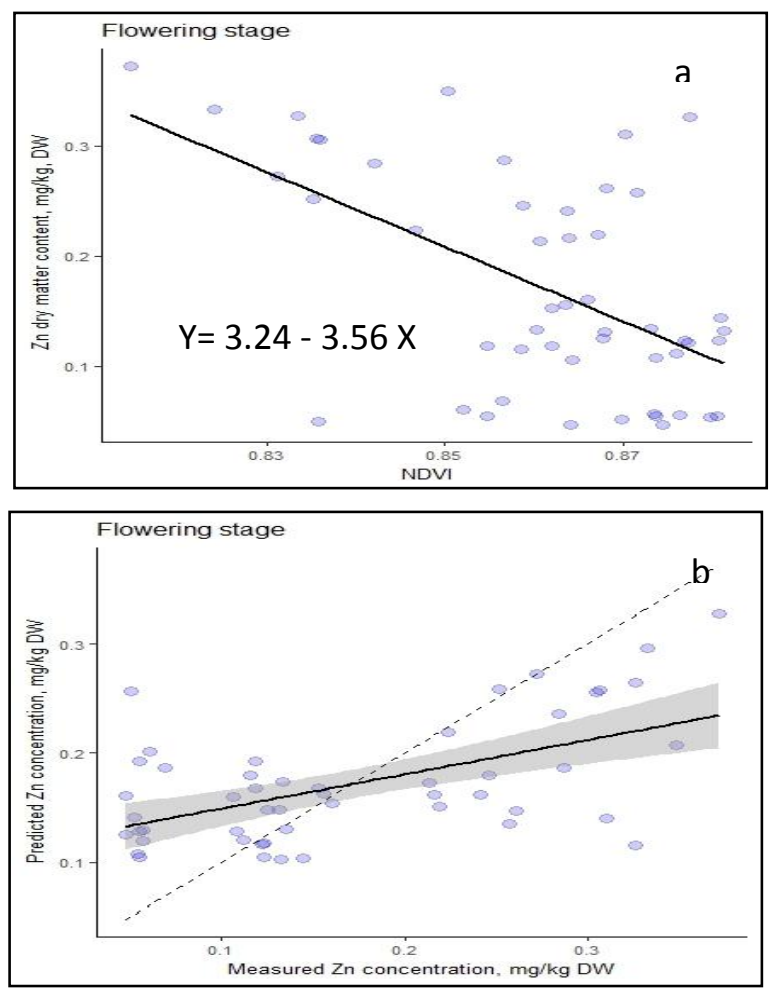

Figure 4 a: (a) Relationship of plant dry mutter Zinc content against SR-680-b, and (b) measured and estimated dry mutter Zin contents of the validation dataset based on SR-680-b at flowering stage. 

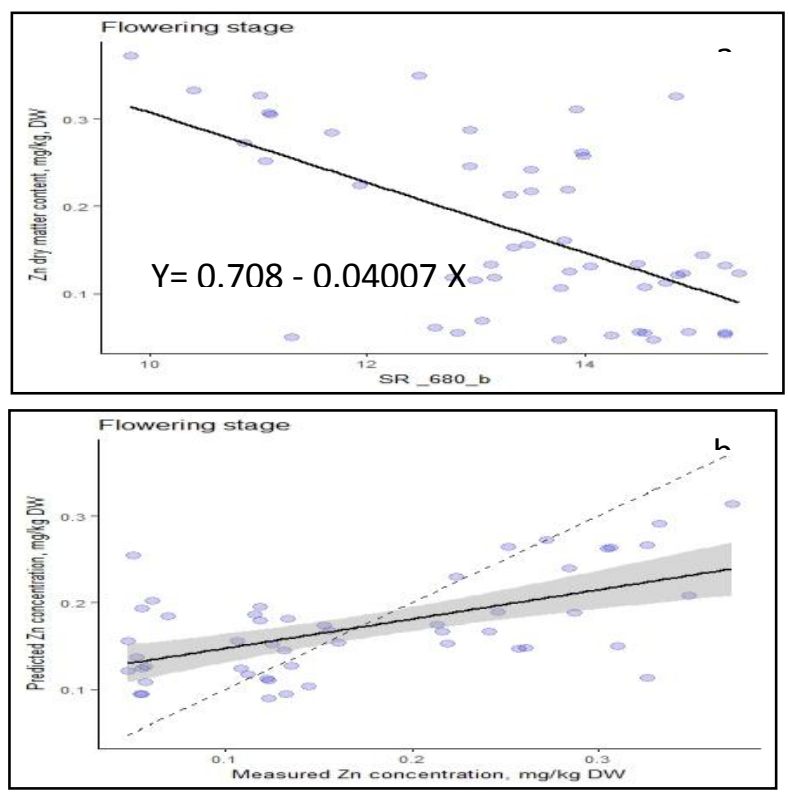

Figure 5 a: (a) Relationship of plant dry mutter Zinc content against NDVI, and (b) measured and estimated dry mutter Zin contents of the validation dataset based on NDVI at flowering stage
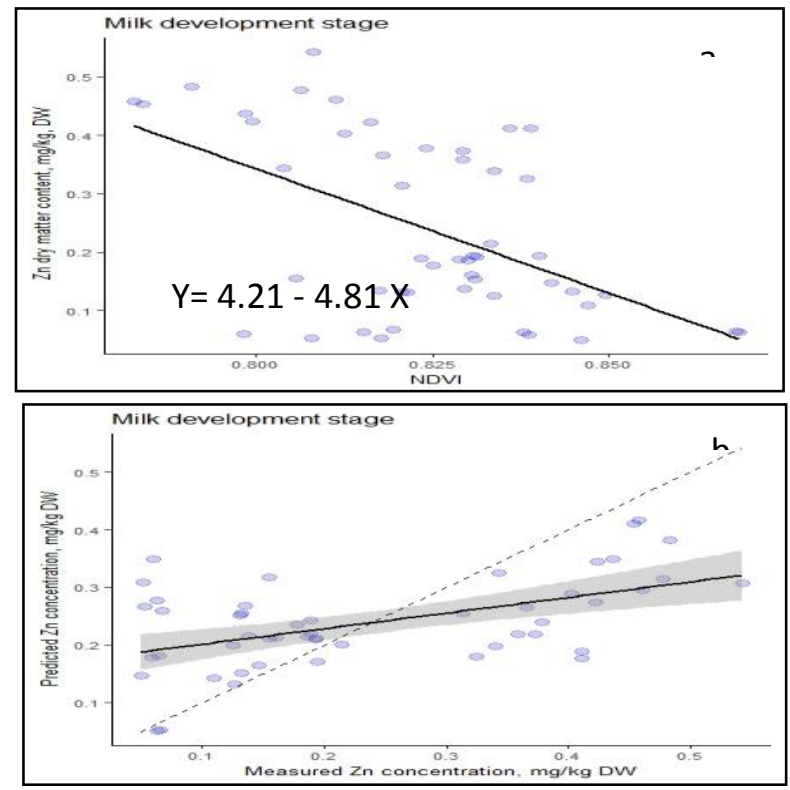

Figure 6 a: (a) Relationship of plant dry mutter Zinc content against NPQI, and (b) measured and estimated dry mutter Zin contents of the validation dataset based on NPQI at flowering stage 

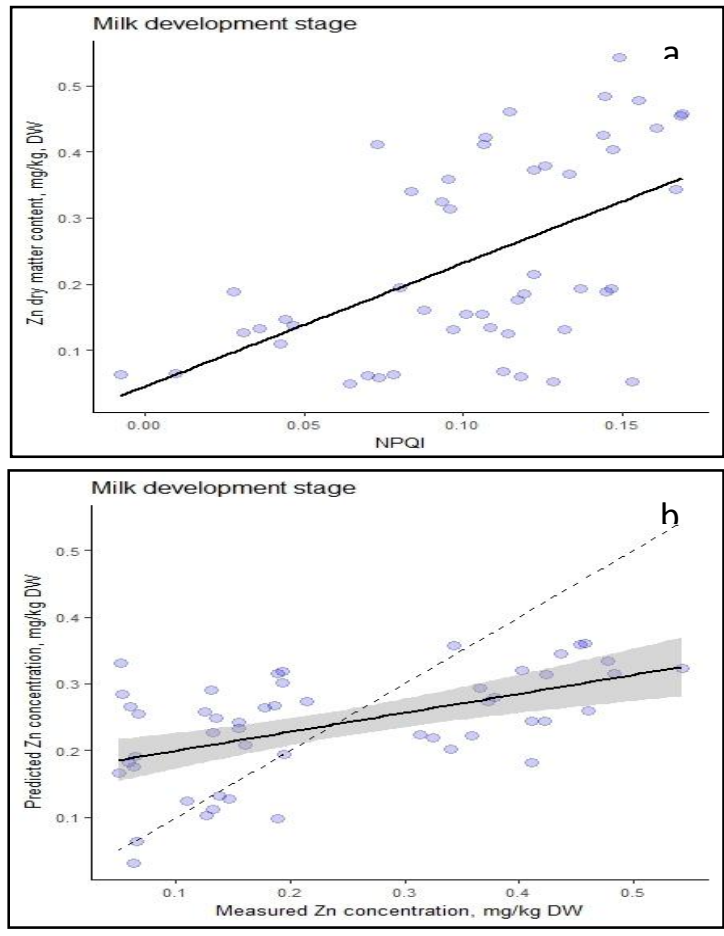

Figure 6 b: (a) Relationship of plant dry mutter Zinc content against NPQI, and (b) measured and estimated dry mutter Zin contents of the validation dataset based on NPQI at milk development stage.

SR-68-b and the validation of prediction statistical model at flowering and milk development stages. NPQI had a positive relationship with the accumulated zinc concentration at flowering and milk development stages with high significant level $(\mathrm{P}-\mathrm{Value}<0.001)$. Fig. (6 a, b) show the relationship between NPQI and the dry mutter $\mathrm{Zn}$ content and the validation of the statistical prediction model.

\section{- Cu accumulation:}

The results of regression analysis between $\mathrm{Cu}$ accumulation in to the plant dry mutter and two-band VIs demonstrated that the almost of two-band VIs have a negative correlation with dry mutter $\mathrm{Zn}$ content, but this negative relationship starts at late growth stage. The negative correlation started to appear at milk development stage. The highest correlated two-band VIs were NDVI b, GNDVI, SR _680_b, PSSR, PSND. All of these VIs had a negative 
relationship with low values of correlation coefficient (r). NDVI b, GNDVI, PSSR had a correlation coefficient $(r)$ values $(-0.36,-0.37,-0.36)$ respectively with significant level at (P-Value < 0.01), but SR _680_b and PSND had a correlation coefficient $(r)$ values $(-0.37$ and -0.36$)$ with significant level at $(\mathrm{P}-$ Value $<0.05)$. From these results we can mentioned that the two-band vegetation indices are low correlated with the Copper accumulation in to the plant dry matter.

\section{2-Metal accumulation into the grains:}

- Relationship of grains heavy metal content against its concentration in irrigation water:

The $r$ and P-Value for the grains Zinc content prediction models based on irrigation water content of $\mathrm{Zn}$ and $\mathrm{Cu}$ are provided in Figures $(7,8,9,10$, and 11).

Copper had a high positive correlation $(r=0.98)$ with high significant $(\mathrm{P}<0.001)$ on $\mathrm{Zn}$ accumulation in the grains. We can refer this result to the positive relationship between the $\mathrm{Cu}$ level add in irrigation water and $\mathrm{Zn}$ accumulation in plant dry mutter at deferent growth stages generally and at the last growth stage (Milk development stage) specially. Equation (1) shows the interaction effect on the accumulation of Zinc into the grains statistical prediction model.

\section{Equation 1}

$$
y=-1.38(\mathrm{ZnCu})^{2}+5.94 \mathrm{ZnCu}+1.25
$$

Equation (2) shows the interaction effect on the accumulation of Copper into the grains statistical prediction model.

\section{Equation 2}

$$
y=-1.38(\operatorname{ZnCu})^{2}+5.94 \mathrm{ZnCu}+1.25
$$


MAI AMER et al.
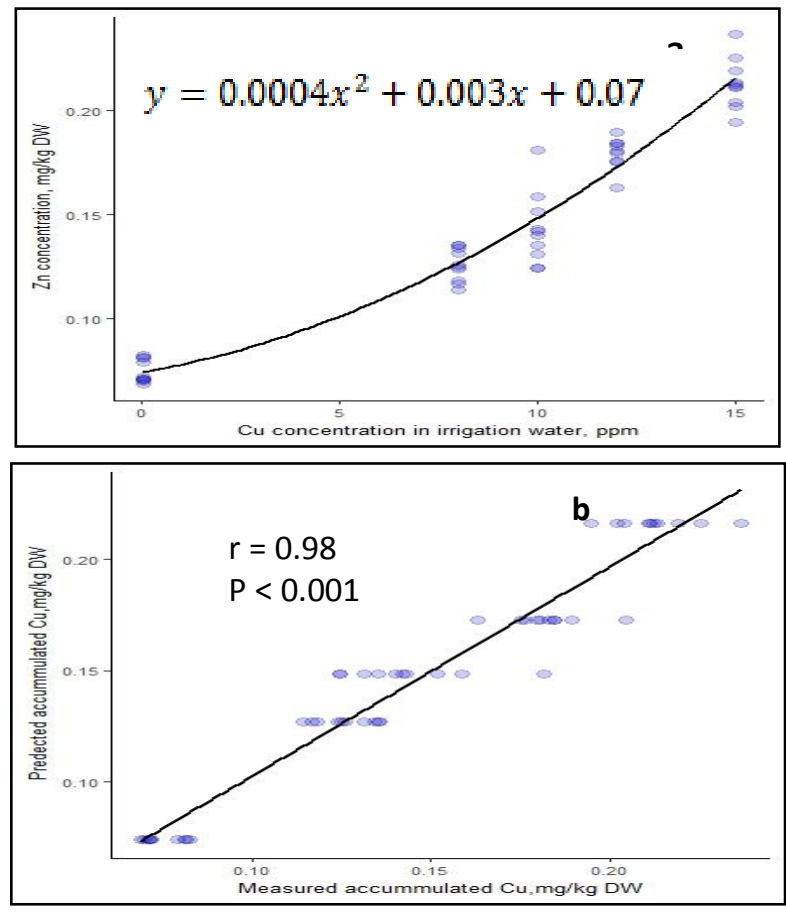

Figure 7: (a) Relationship of wheat grains Zinc content against irrigation water Copper content, and (b) measured and estimated grains Zin contents of the validation dataset based on Copper concentration in irrigation water

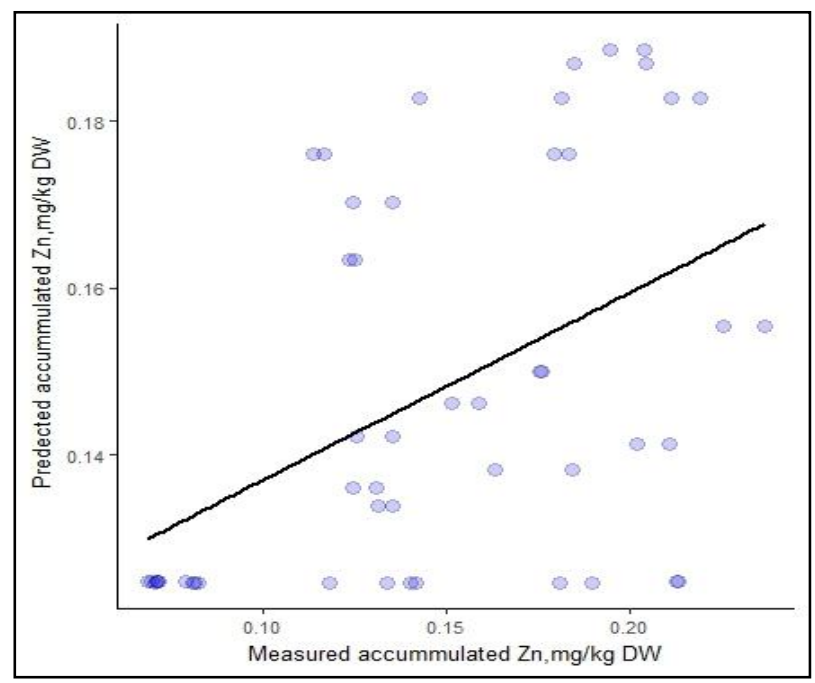

Figure 8: Measured and estimated wheat grains $\mathrm{Zn}$ contents of the validation dataset based on the interaction between the irrigation water content of Zinc and Copper 
Figure (9) illustrates the relationship between the $\mathrm{Zn}$ concentration in irrigation water and $\mathrm{Cu}$ accumulation into the grains. The figure shows a polynomial negative relationship between Zinc concentrations add in irrigation water and the Copper accumulated into the grains with significant level $(\mathrm{P}-$ Value $<0.01)$.
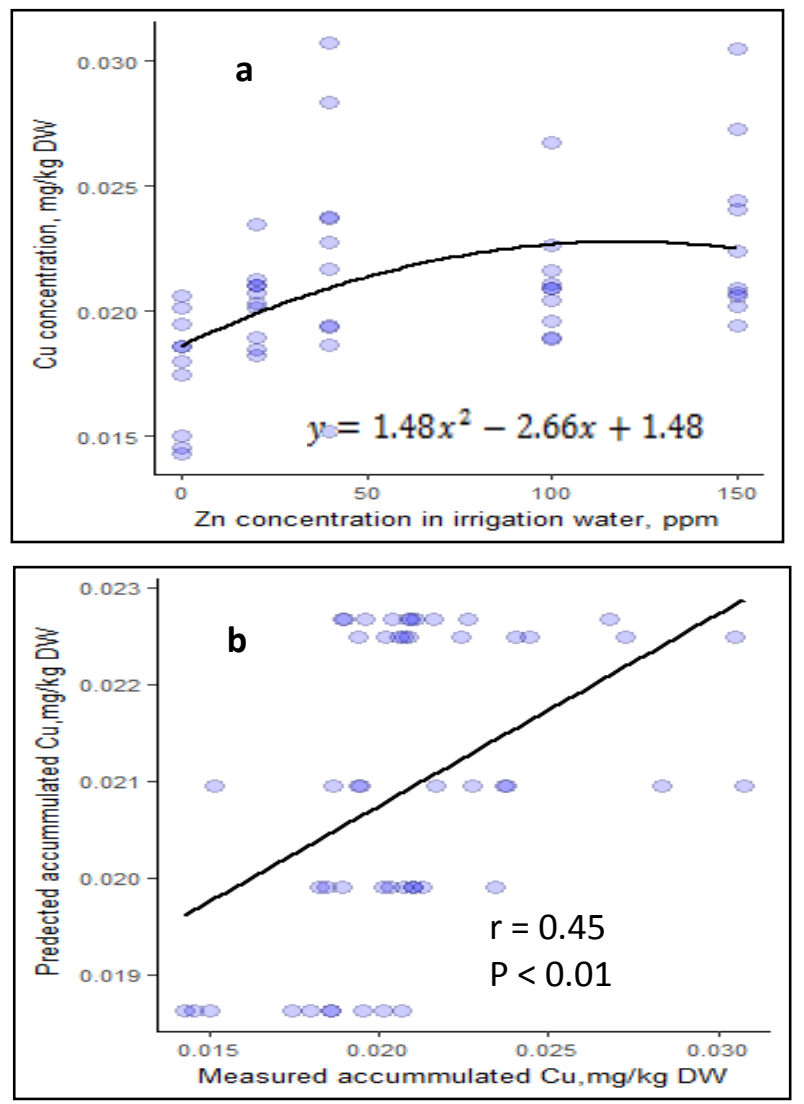

Figure 9: (a) Relationship of wheat grains Copper content against irrigation water Zinc content, and (b) measured and estimated grains $\mathrm{Cu}$ content of validation dataset based on $\mathrm{Zn}$ add in irrigation water.

The irrigation water Copper content had a polynomial positive relationship with $\mathrm{Cu}$ concentration in grains as illustrated in Figure (10) with significant level (P-Value $<0.05)$. The interaction between the irrigation water content of $\mathrm{Zn}$ and Its content of $\mathrm{Cu}$ had highest correlation with the Copper 

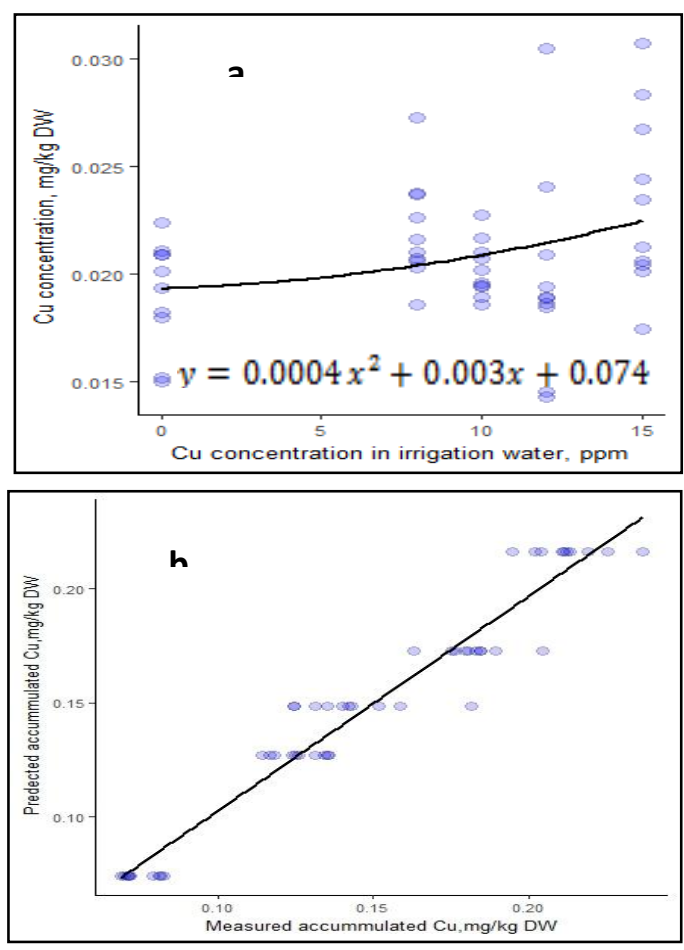

Figure 10: (a) Relationship of wheat grains Copper content against irrigation water Copper content, and (b) measured and estimated grains $\mathrm{Cu}$ content of validation based on $\mathrm{Cu}$ add in irrigation water

accumulation into the grains with high significant level ( $\mathrm{P}-$ Value <0.001). Figure (11) shows the validation of prediction statistical model of interaction effect on grains Copper content.

Relationship of grains heavy metal content against vegetation indices (VIs):

Two-band VIs had an insignificant relationship with $\mathrm{Zn}$ accumulation in grains. In contrast $\mathrm{Cu}$ accumulation into the grains had a significant relationship with the almost of two-band VIs with low correlation coefficient. NDVI, GNDVI, RNDVI, SR - 680, and NPQI had a significant correlation with grains $\mathrm{Cu}$ content at (P-Value <0.05) and $\mathrm{r}(-0.30,-0.31,-0.30,-0.33$, and 0.36) respectively. NPCI and PSSR had a highest correlation with $\mathrm{Cu}$ phytoaccumulation into the grains with highest significant level (P-Value < $0.01)$ and $(r)$ values $(-0.39,-0.42)$. 


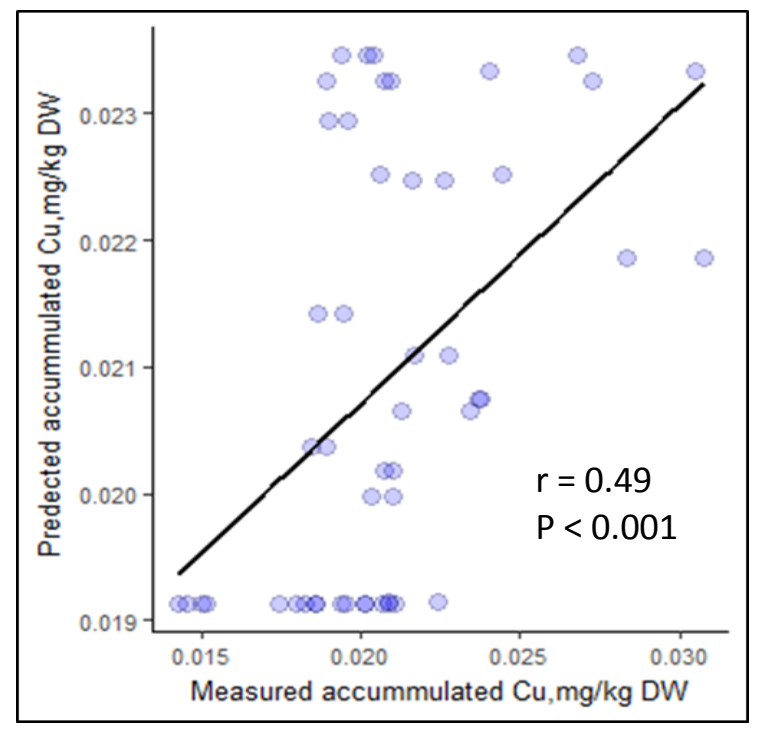

Figure 11: (a) Relationship of wheat grains Copper content against irrigation water Copper content, and (b) measured and estimated grains $\mathrm{Cu}$ content of validation based on $\mathrm{Cu}$ add in irrigation water

\section{Conclusions:}

Results of present study demonstrate that hyperspectral reflectance data, as well as studied VIs appears to have potentials for monitoring the phytoaccumulation of $\mathrm{Zn}$ into above-ground parts of wheat. The hyperspectral vegetation indices had insignificant correlation with $\mathrm{Zn}$ accumulation in to the grains, but it had a significant negative relationship with $\mathrm{Cu}$ concentration in grains with low correlation coefficient values.

\section{Acknowledgments}

The authors acknowledge the financial support from the Egyptian Ministry of higher education and the Egyptian missions.

\section{REFERENCES}

[1] Babula, P., Adam, V., Opatrilova, R., Zehnalek, J., Havel, L. and Kizek, R., (2008). Uncommon heavy metals, metalloids and their plant toxicity: a review. Environmental Chemistry Letters, 6(4), pp. 189-213. 
[2] Changwei Tana, A. Samantab, X. Jina, Lu Tonga, Ch. Maa, W. Guoa, Y. Knyazikhinc, and R. B. Mynenic (2013). Using hyper spectral vegetation indices to estimate the fraction of Photosynthetically active radiation absorbed by corn canopies, International Journal of Remote Sensing, Vol. 34, No. 24, 8789-8802

[3] Chatterjee, C., Gopal, R. and Dube, B., (2006). Physiological and biochemical responses of French bean to excess cobalt. Journal of Plant Nutrition, 29(1), pp. 127-136.

[4] Chi, G.Y., Shi, Y., Chen, X., Ma, J. and Zheng, T.H., (2012). Effects of metal stress on visible/near-infrared reflectance spectra of vegetation. Advanced Materials Research, Trans Tech Publ, pp. 2735-2738.

[5] Clemens, S., (2006). Toxic metal accumulation, responses to exposure and mechanisms of tolerance in plants. Biochimie, 88(11), pp. 17071719.

[6] Clemens, S., 2001. Molecular mechanisms of plant metal tolerance and homeostasis. Planta, 212(4), pp. 475-486.

[7] Elmetwalli A. M. H.(2008) Remote Sensing as a Precision Farming Tool in the Nile Valley, Egypt, PhD Theses, the School of Biological and Environmental Sciences, University of Stirling, Stirling, FK9 4LA, UK.

[8] Gaur, A. and Adholeya, A., (2004). Prospects of arbuscular mycorrhizal fungi in phytoremediation of heavy metal contaminated soils. Curr Sci, 86(4), pp. 528-534.

[9] Ivanova, E., Kholodova, V. and Kuznetsov, V.V., (2010). Biological effects of high copper and zinc concentrations and their interaction in rapeseed plants. Russian Journal of Plant Physiology, 57(6), pp. 806814.

[10] Kamran Sardar, *Shafaqat Ali, Samra Hameed, Sana Afzal, Samar Fatima, Muhammad Bilal Shakoor, Saima Aslam Bharwana, Hafiz Muhammad Tauqeer, (2013). Heavy Metals Contamination and what are the Impacts on Living Organisms. Greener Journal of Environmental Management and Public Safety, 2(4), pp. 172-179.

[11] Lichtenthaler, H.K., AČ, A., Marek, M.V., Kalina, J. and Urban, O., (2007). Differences in pigment composition, photosynthetic rates and chlorophyll fluorescence images of sun and shade leaves of four tree species. Plant Physiology and Biochemistry, 45(8), pp. 577-588. 
[12] Mahmood, T. and Islam, K., (2006). Response of rice seedlings to copper toxicity and acidity. Journal of Plant Nutrition, 29(5), pp. 943957.

[13] Nagajyoti, P., LEE, K. and Sreekanth, T., (2010). Heavy metals, occurrence and toxicity for plants: a review. Environmental Chemistry Letters, 8(3), pp. 199-216.

[14] Rathod, P.H., Brackhage, C., VAN DER MEER, FREEK D, Müller, I., Noomen, M.F., Rossiter, D.G. and Dudel, G.E., (2015). Spectral changes in the leaves of barley plant due to phyto remediation of metals-results from a pot study. European Journal of Remote Sensing, 48, pp. 283-302.

[15] SHI, T., LIU, H., CHEN, Y., WANG, J. and WU, G., (2016). Estimation of arsenic in agricultural soils using hyperspectral vegetation indices of rice. Journal Of Hazardous Materials, 308, pp. 243-252.

[16] Spomer, L.A., Berry, W.L. and Tibbitts, T.W., (1997). Plant culture in solid media. Plant Growth Chamber Handbook'. (Eds RW Langhans, TW Tibbitts) pp, , pp. 105-118.

[17] Vernay, P., Gauthier-Moussard, C. and Hitmi, A., (2007). Interaction of bioaccumulation of heavy metal chromium with water relation, mineral nutrition and photosynthesis in developed leaves of Lolium perenne L. Chemosphere, 68(8), pp. 1563-1575.

[18] Wood CW, Reeves DW, Himelrick DG. 1993. Relationships between chlorophyll mete $\mathrm{r}$ readings and leaf chlorophyll concentration, $\mathrm{N}$ status, and crop yield : A review. Proceedings of Agricultural Society of New Zealand, 23: 1-9. 
الخصائص الطيفية لتقدير تراكم المعادن الثقيلة في نباتات وحبوب القمح

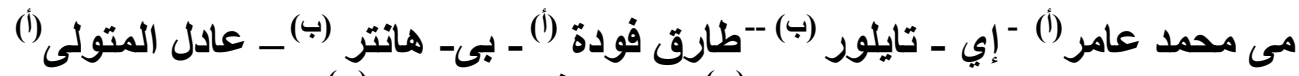

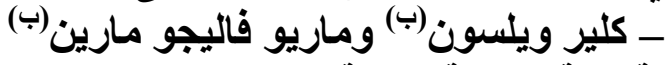

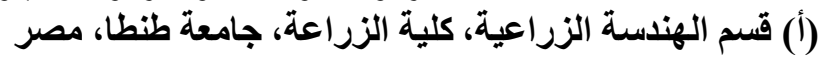
(ب) قسم العلوم البيولوجية والبيئية، كلية العلوم الطبيعية، جامعة ستيرلنج ، ستيرلنج، أسكتلندا،

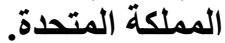

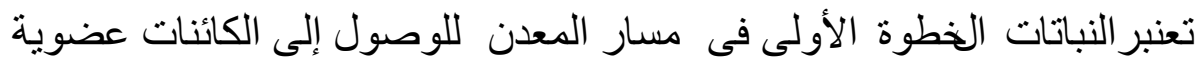

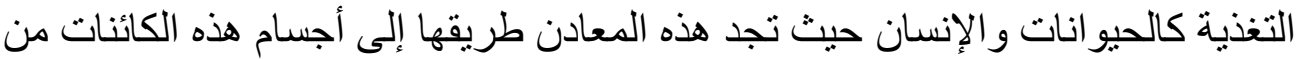

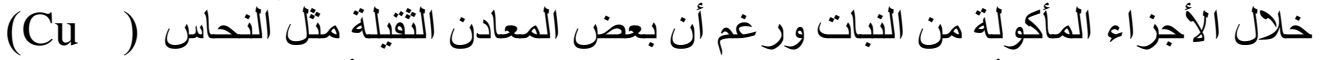

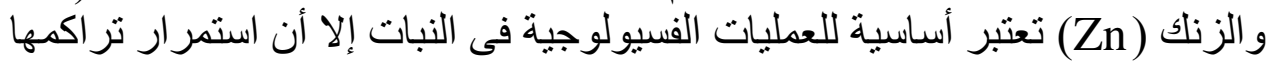

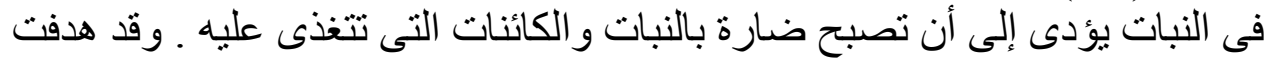

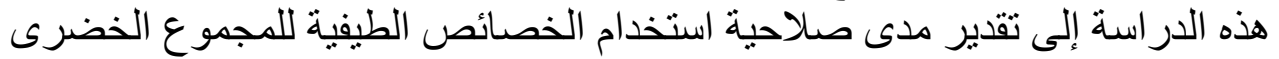

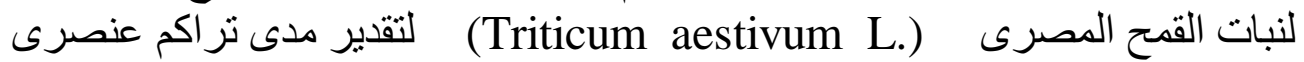
النحاس و الزنك فى المادة الجافة وحبوب القمح المروى بمياه تحتوى تركيز ات مرتفعة

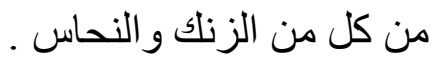

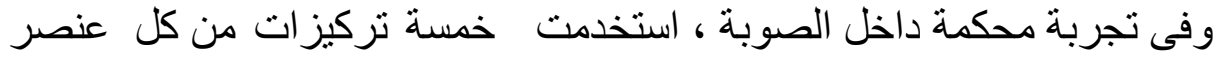

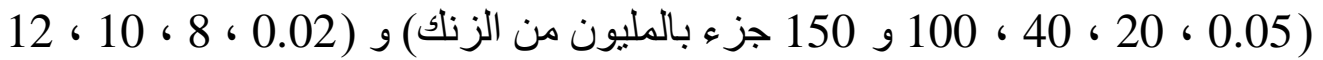

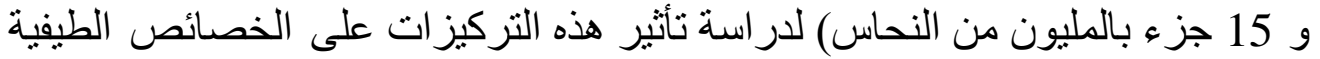

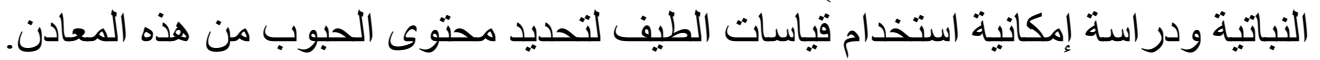

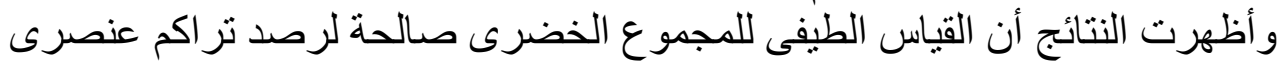

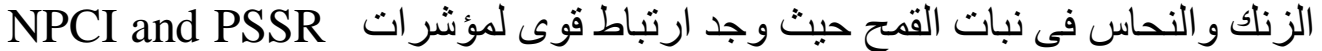

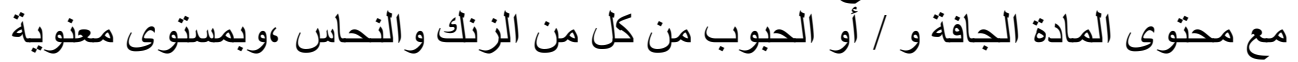

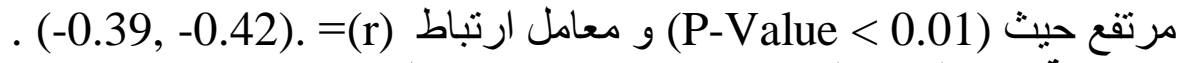

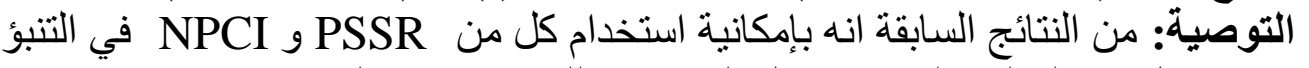

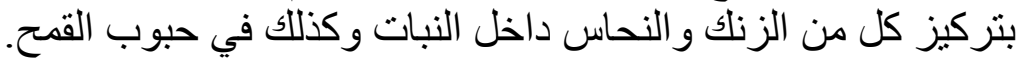

